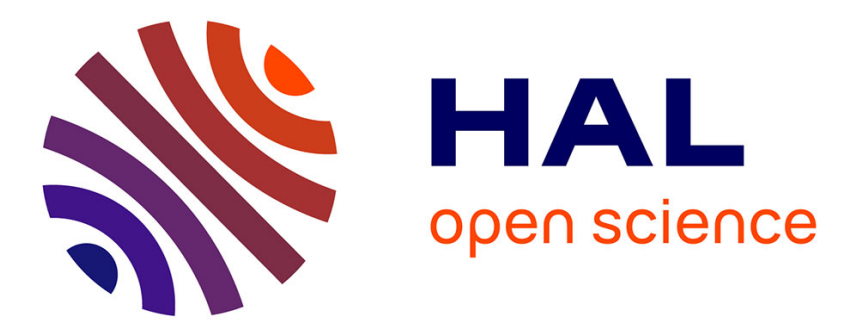

\title{
Resection of the third and four portions of the duodenum
}

\author{
M. Seman, F. Kasereka-Kisenge, A. Taieb, S. Noullet, C. Trésallet
}

\section{To cite this version:}

M. Seman, F. Kasereka-Kisenge, A. Taieb, S. Noullet, C. Trésallet. Resection of the third and four portions of the duodenum. Journal of Visceral Surgery, 2019, 156, pp.45 - 49. 10.1016/j.jviscsurg.2018.11.002 . hal-03486538

\section{HAL Id: hal-03486538 \\ https://hal.science/hal-03486538}

Submitted on 20 Dec 2021

HAL is a multi-disciplinary open access archive for the deposit and dissemination of scientific research documents, whether they are published or not. The documents may come from teaching and research institutions in France or abroad, or from public or private research centers.
L'archive ouverte pluridisciplinaire HAL, est destinée au dépôt et à la diffusion de documents scientifiques de niveau recherche, publiés ou non, émanant des établissements d'enseignement et de recherche français ou étrangers, des laboratoires publics ou privés.

\section{다)(1) $(5$}

Distributed under a Creative Commons Attribution - NonCommercial| 4.0 International 


\title{
Resection of the third and four portions of the duodenum
}

\author{
Marie Seman ${ }^{1}$, Faustin Kasereka-Kisenge ${ }^{2}$, Anna Taieb ${ }^{3}$, Noullet Séverine ${ }^{3}$, \\ Christophe Trésallet ${ }^{3}$
}

1-Service de Chirurgie Digestive, Centre Hospitalier de Marne la Vallée- Jossigny, 2-4 Cours

de la Gondoire 77600 Jossigny

2-Département de chirurgie, Clinique Universitaire de Kisangani, BP 1787 Kisangani,

République Démocratique du Congo (RDC)

3 -Service de Chirurgie Générale, Viscérale et Endocrinienne, 47-83 bd de l'Hôpital, CHU

Pitié-Salpêtrière 75013 Paris, Pierre et Marie Curie- Sorbonne Universités (Paris 6)

\section{Introduction}

There are few indications for isolated resection of the third (D3) and fourth (D4) segments of the duodenum (without pancreatoduodenectomy). Such a resection can be necessary under two circumstances:

- in elective surgery, for tumors of D3 or D4, that do not invade the pancreas, or for colonic cancer invading the duodenojejunal flexure [1].

- in emergency surgery as part of a salvage operation to preserve pancreatic parenchyma: in case of aortoduodenal fistula or more often prosthetic-duodenal fistula, or in case of abdominal trauma, (usually penetrating, especially gunshot wound), with loss of substance of a portion of the duodenum [2].

This technique is only feasible when both D3 and D4 are completely removed. If complete excision is not possible, then a duodenojejunostomy technique should be considered [3].

The difficulty of this operation resides in restoration of duodenal continuity, because of the anatomic location of the superior mesenteric axis. 


\section{1- Anatomical reminder (Figure 1)}

The duodenum is retroperitoneal, fixed posteriorly behind the root of the transverse colon. The first portion of the duodenum (D1), located between the pylorus and the gastroduodenal artery, is divided into two parts, the proximal part being free, and the distal part fixed, while D2 and D3 are fixed by close vascular attachments with the pancreas. D2 is where the main bile duct and the main pancreatic duct typically open into the duodenal lumen through the papilla of Vater. D4 is located to the left of the superior mesenteric vessels; it is mobile, but fixed posteriorly by the ligament of Treitz.

The vascularization of D2 and the proximal part of D3 is intimately linked to the vascular supply of the pancreas, arising from the anterior and posterior duodenopancreatic arcades, arising from the gastroduodenal and superior mesenteric arteries.

The vascularization of the distal portion of D3 and D4 is assured by the collateral branches of the duodenopancreatic arcades and the initial left branches of the superior mesenteric artery. This vascularization is variable and in $25 \%$ of cases, D4 does not have its proper vascular supply. The vascularization of D4 is therefore tenuous and it is not recommended to perform an anastomosis on this segment [4].

\section{2- Installation - Incision (Figure 2)}

The patient is positioned supine (dorsal decubitus), a beanbag under the tip of the scapulas, both arms extended at right angles. The incision depends on the anatomy of the patient, the circumstances of the operation (elective or emergency) and the duodenal disease leading to surgery. In elective surgery, a bilateral subcostal incision can be proposed for patients with a relatively horizontal costal margin; 
otherwise, in the emergency setting, an upper midline incision is the approach of choice.

\section{3- Duodenopancreatic mobilization (Figure 3)}

To expose the duodenal C-loop, the hepatic flexure is taken down as far as the mid-transverse colon, exposing the anterior aspect of the duodenal loop as far as the right portion of D3. Next, the posterior parietal peritoneum along the right border of D2 is incised and the duodenal C-loop is mobilized posteriorly in the avascular plane anterior to the right kidney, the right ureter, and the genital veins until the anterior aspect of the inferior vena cava is reached.

\section{4 - Mesenteric root mobilization (Figure 4)}

The exposition of D3 can be facilitated by mobilization of the mesenteric root, reflecting the ileo-cecum cephalad while mobilizing the hepatic flexure. After complete right colo-parietal mobilization, the mesenteric root is incised exposing the retro-mesocolic portion of D3. Thus, the entire right colonic loop and small intestines can be mobilized and displaced cephalad and to the left. D4 is then mobilized by dividing the ligament of Treitz and opening the peritoneal duodeno-jejunal fossae.

\section{5- Division of the jejunum (Figure 5)}

After completely freeing the anterior and posterior aspects of D4, the duodenal resection begins by dividing the first jejunal loop with a linear stapler. Hemostasis of the jejunal vessels is assured by ligation, thermofusion or high-frequency ultrasonic instrumentation.

\section{6- Jejunal pass under (Figure 6)}


Once the jejunum is completely freed, it can be moved from left to right behind the superior mesenteric vessels.

Next D3 and D4 are mobilized as far as the genu inferius of the C-loop. Separation of the duodenum from the inferior border of the pancreas requires careful individual hemostasis of all the small vessels running between the two organs.

\section{7- Duodeno-jejunal anastomosis (Figure 7)}

The duodenum is then divided at the level of the genu inferius. If the level of division should be more proximal, the position of the papilla must be identified by passage of an instrument (stylet or catheter) through the papilla via the cystic duct. If a transcystic drain is used, it should be removed at the end of the operation.

The jejunal loop is brought to the right of the superior mesenteric vascular axis and in front of the colon, to the level of D2 in preparation for the duodeno-jejunal anastomosis. A mechanical anastomosis is not recommended because it would create the risk of papillary disinsertion. The duodeno-jejunal anastomosis, is best performed handsewn end-toend with interrupted or continuous absorbable 3/0 suture material.

\section{8- Drainage and closure (Figure 8)}

This duodeno-jejunal anastomosis is at high risk for fistula because of the potentially tenuous vascular supply to D2. Water-tightness should be tested by infusion of methylene blue: once the anastomosis is shown to be water-tight, a tubular-lamellar drain module is inserted near the anastomosis. The value of duodenal exclusion has not been shown, and if performed, would impede ultimate access to the papilla. This exclusion has not been shown to decrease the risk of fistula or mitigate its 
consequences. Conversely, it seems indispensable to foresee the need for early enteral nutrition by placing a trans-anastomotic naso-jejunal catheter or by a feeding jejunostomy. Insertion of a nasogastric suction tube completes the operation.

\section{References}

[1] Bouvier S, Le Borgne J, Lehur PA, et al. Résection de l'angle duodéno-jéjunal pour tumeur. J Chir 1997; 134: 122-127.

[2] Schoell T, Manceau G, Chiche L, et al. Surgery for secondary aortoenteric fistula or erosion (SAEFE) complicating aortic graft replacement: a retrospective analysis of 32 patients with particular focus on digestive management. World J Surg 2015; 39: 283-91.

[3] Deguines JB, Verhaeghe P, Regimbeau JM. Side-to-end duodenojejunostomy (Gregoire's technique modified by Stoppa). J Visc Surg 2013; 150: 29-32.

[4] Landier JF, Calmat A, Honnart F, et al. Nouvelles acquisitions sur la vascularisation artérielle de la $3^{\text {ième }}$ et la $4^{\text {ième }}$ portion du duodénum. $J$ Chir (Paris) 1977; 113: 405-12.

\section{Conflicts of interest: none}

Figures 
2 aide: assistant, opérateur: operating surgeon; instrumentiste: instrument nurse

$3 \ldots$ 


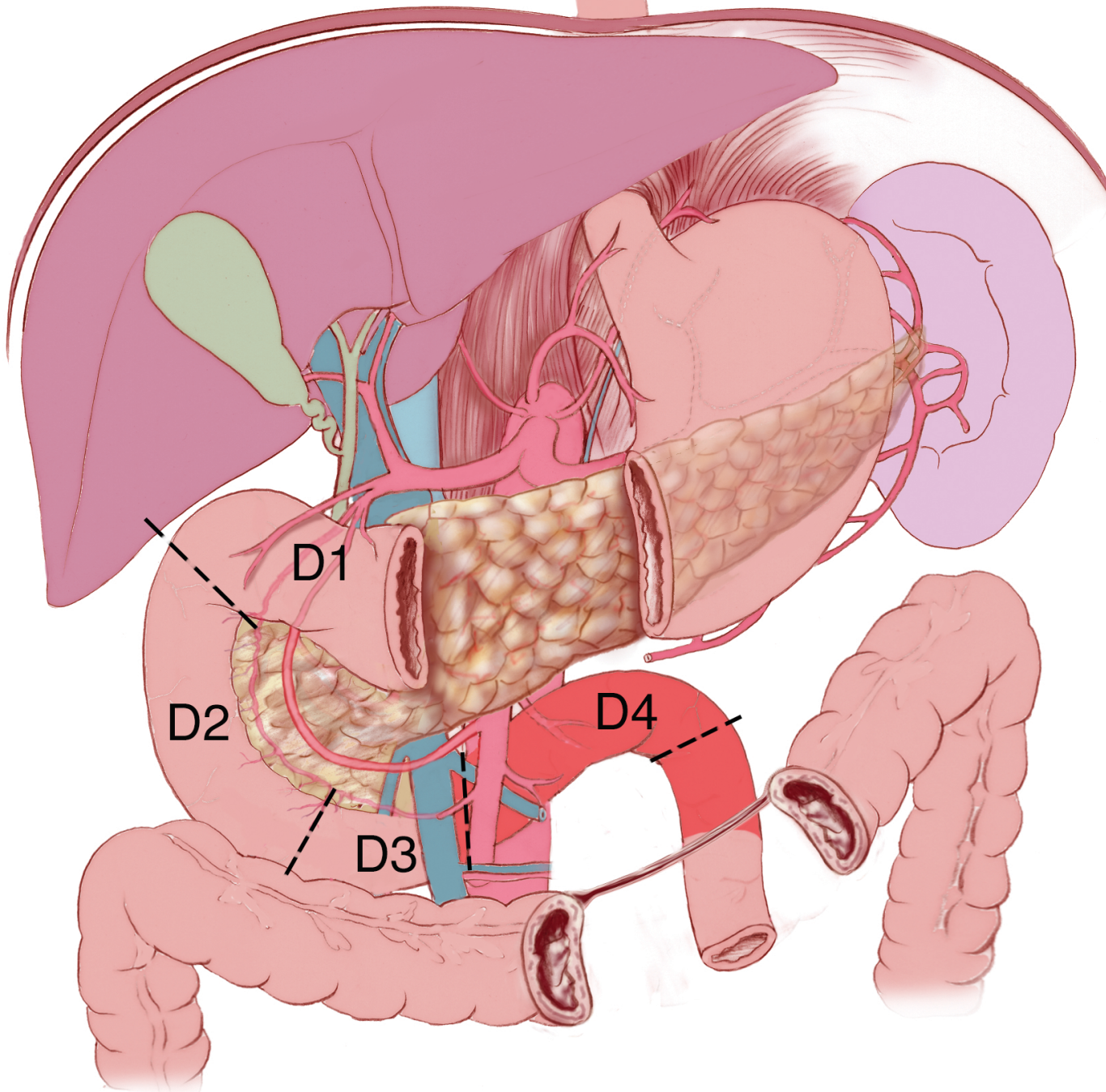




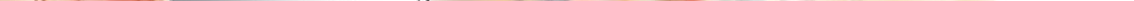




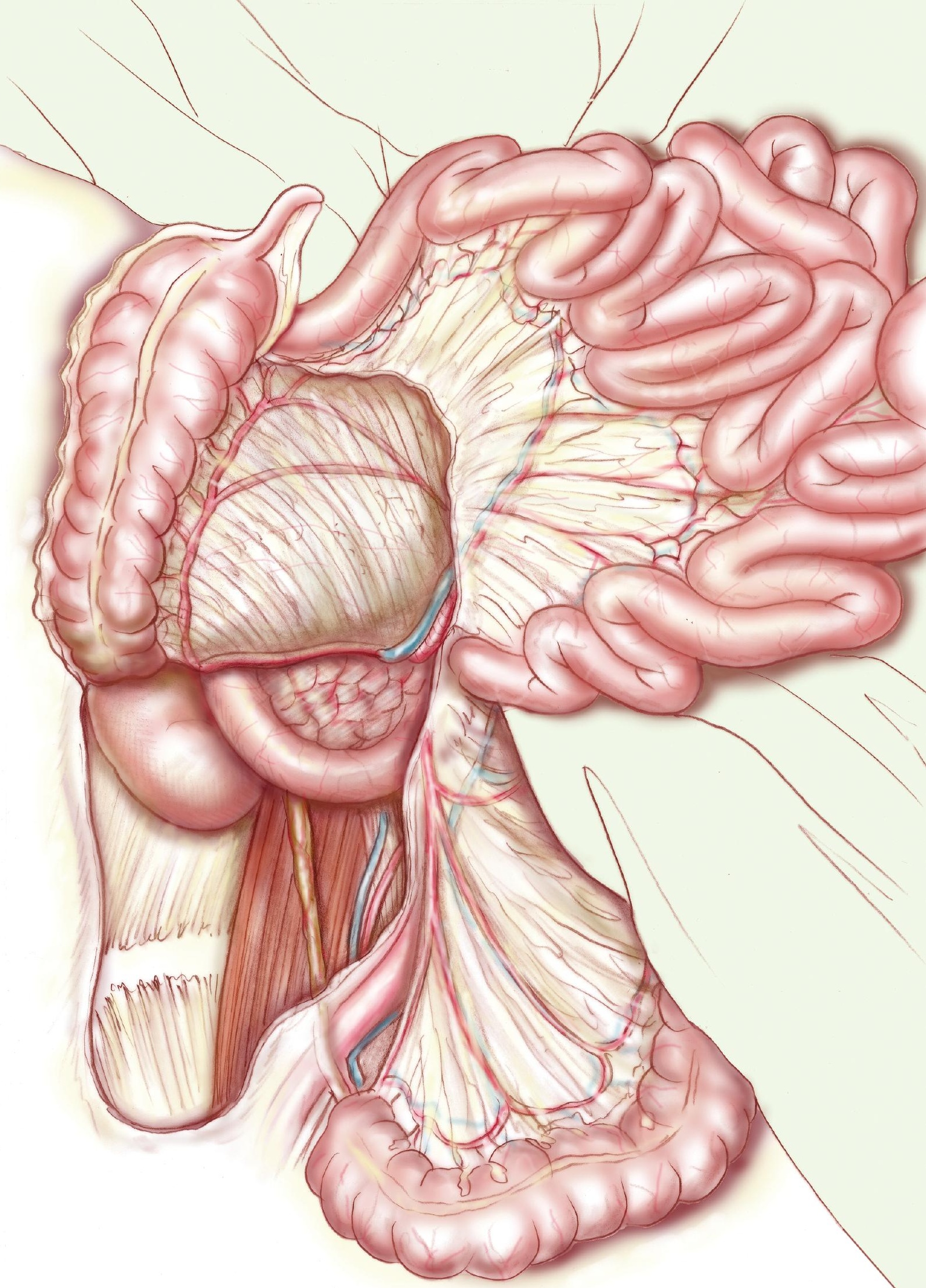




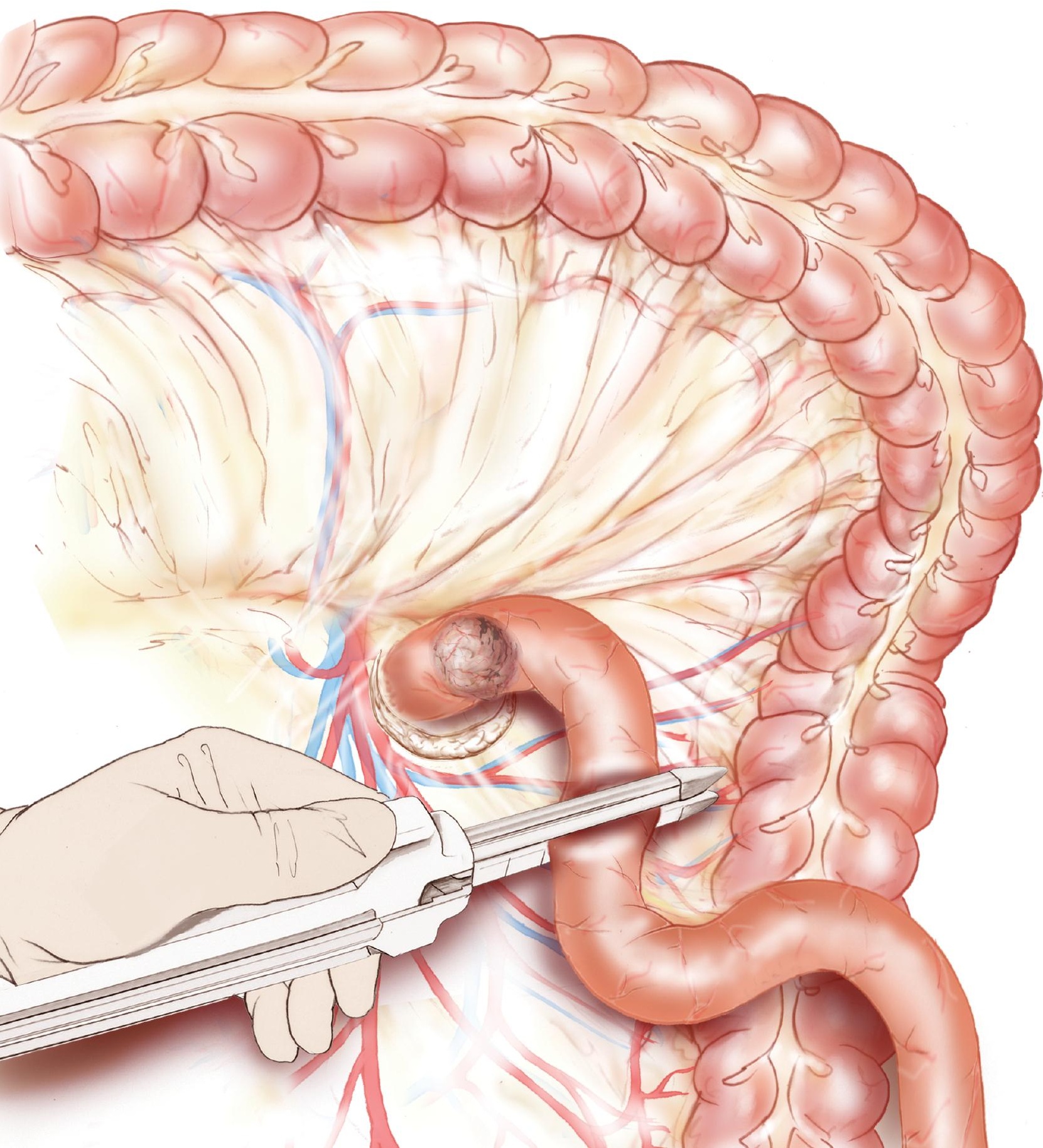





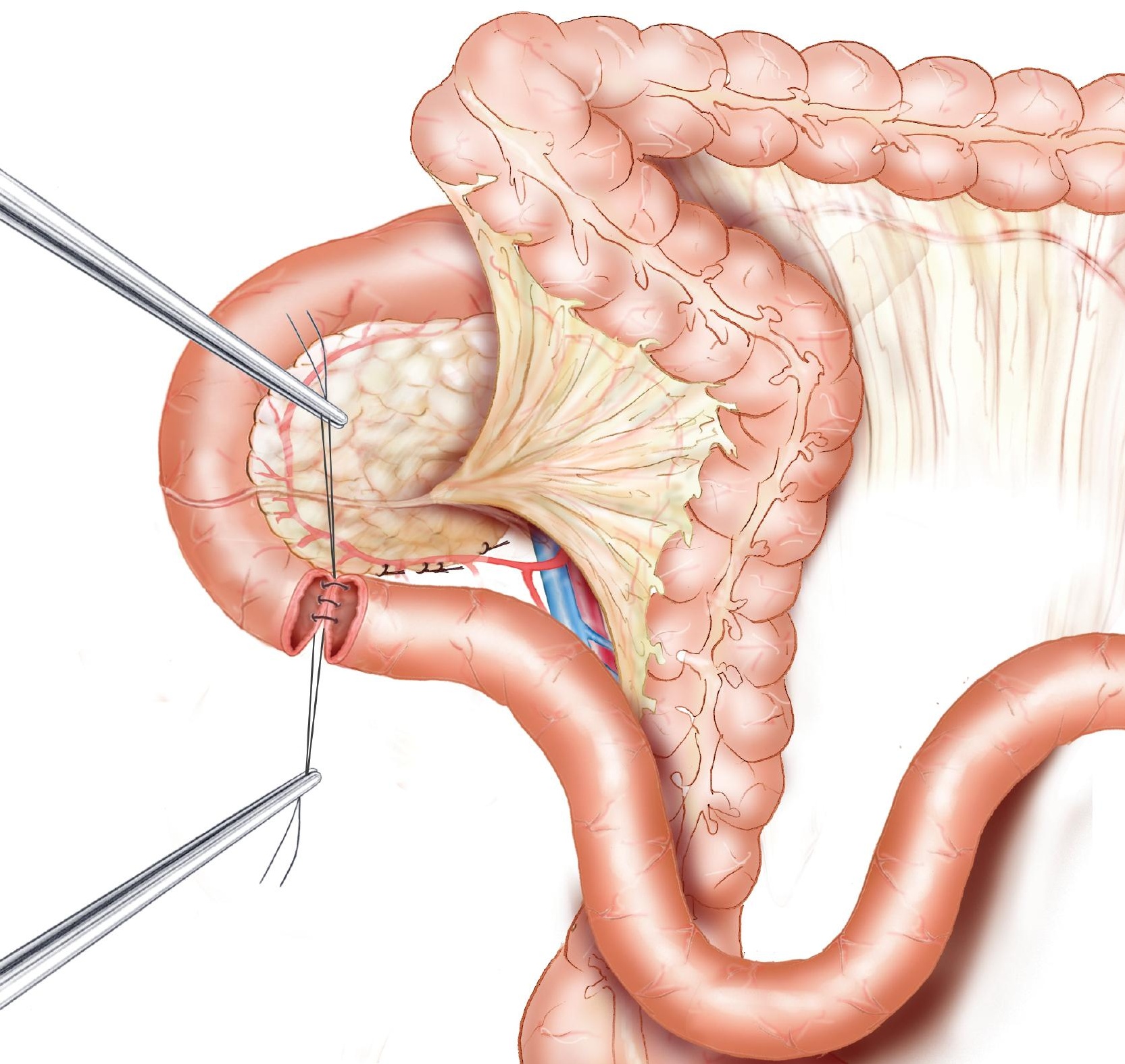




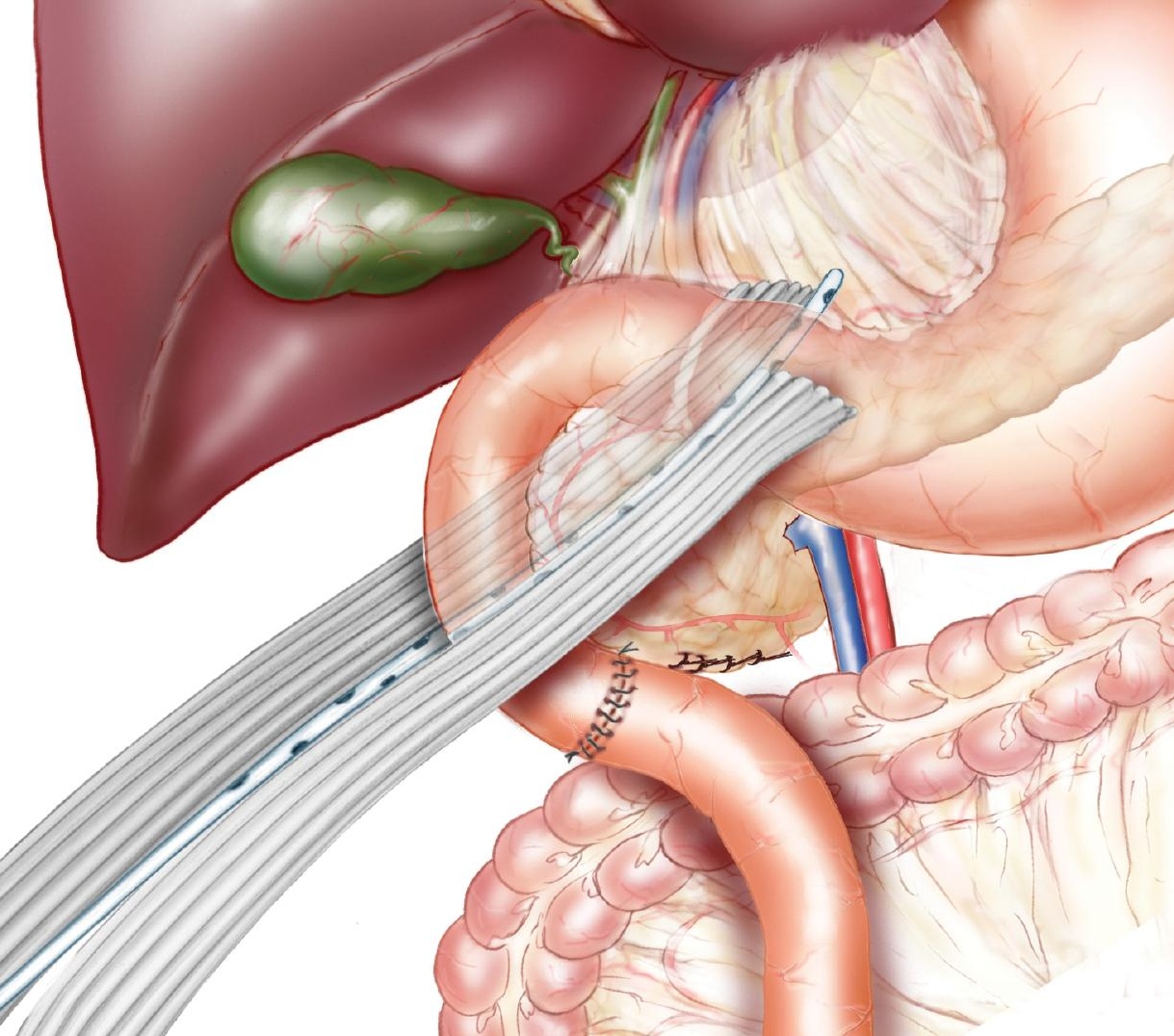

